\title{
Solitary primary subcutaneous hydatid cyst of the buttock - Case report and literature review
}

\author{
Monsef Elabdi ${ }^{\mathrm{a},{ }^{*}}$, Hassane Zejjari $^{\mathrm{b}}$, Abederrahmane Elwali ${ }^{\mathrm{c}}$, Redouane Roukhsi ${ }^{\mathrm{d}}$, Jamal Louaste $^{\mathrm{b}}$, \\ Laarbi Amhajji ${ }^{b}$
}

${ }^{a}$ Department of Orthopaedic Surgery, Military Hospital of Laayoun, Laayoun, Morocco.

${ }^{b}$ Department of Orthopaedic Surgery, Military Hospital of Meknes, Meknes, Morocco.

${ }^{c}$ Department of Anesthesiology and Intensive Care, Military Hospital of Laayoun, Laayoun, Morocco.

${ }^{d}$ Department of Radiology, Military Hospital of Laayoun, Laayoun, Morocco.

\begin{abstract}
Hydatidosis is an endemic parasitic disease affecting in most cases the parenchymal organs. The involvement of the soft tissue is a rare pathology that, left untreated, can lead to rupture and potentially catastrophic anaphylaxis. In this article, we describe the case of a 42-year-old male who developed a subcutaneous hydatid cyst in the buttock as a solitary primary localization. Consequently, the patient underwent a successful surgical excision with uneventful post-operative recovery.

Keywords: Hydatid Cyst; echinococcus granulosis; subcutaneous; soft tissue; buttock
\end{abstract}

\section{INTRODUCTION}

Hydatid cyst (HC) is an endemic disease in Mediterranean Basin, Middle East, South America, East Africa, Central Asia, and Australia ${ }^{[1,2]}$. This happens principally in areas where dogs are used to herd grazing animals, particularly sheep ${ }^{[3]}$.

Infection is caused by Echinococcus granulosus ${ }^{[4]}$. The involvement of one or multiple organs is a known event. The liver and lung are the most common organs involved (> 85\%) and represent generally primary foci ${ }^{[2,5,6]}$. However, primary subcutaneous soft tissue hydatitosis is very rare ${ }^{[1,7,8]}$. To our knowledge, few cases have been reported in the literature. We present the case of a subcutaneous hydatid cyst in the buttock region as a primary site without involving other rentals.

\section{CASE REPORT}

\footnotetext{
* Corresponding author: Monsef Elabdi

Mailing address: Department of Orthopaedic Surgery, Military Hospital of Laayoun, 70000 of Laayoun, Laayoun, Morocco.

E-mail: elabdimonsef@gmail.com

Received: 24 December 2020 / Accepted: 05 March 2021
}

A 42-year-old soldier presenting with a two-year history of the gradual development of a voluminous painless mass on his right hip, without any history of trauma or infection. Since his childhood, the patient was living in an urban area, which is not endemic for hydatid cyst. He weighs $72 \mathrm{~kg}$ with a height of $1.73 \mathrm{~m}$ and who's the BMI of 24.05, with good general conditions. Clinical examination revealed a painless right buttock mass, renitent on palpation, poorly limited, measured approximately $20 \mathrm{~cm}$ in greatest dimension (Figure 1). The overlying skin was distended without associated inflammatory signs. Hip X-ray showed no abnormalities. Ultrasound examination (UE) and magnetic resonance imagining (MRI) depicted a superficial multilobed formation, adjacent to the buttock muscles, with multiple cystic lesions (Figure 2 and 3). This was considered as a hydatid cyst. Hydatid serology for antibodies to Echinococcus granulosus antigens was negative. Complete blood count (CBC) did not reveal eosinophilia and biochemistry findings were normal. In the extended assessment, a computed tomography (CT) scan of the chest and abdomen was within the normal range and excluded pulmonary or hepatic involvement.

The patient underwent surgical excision by pericys- 


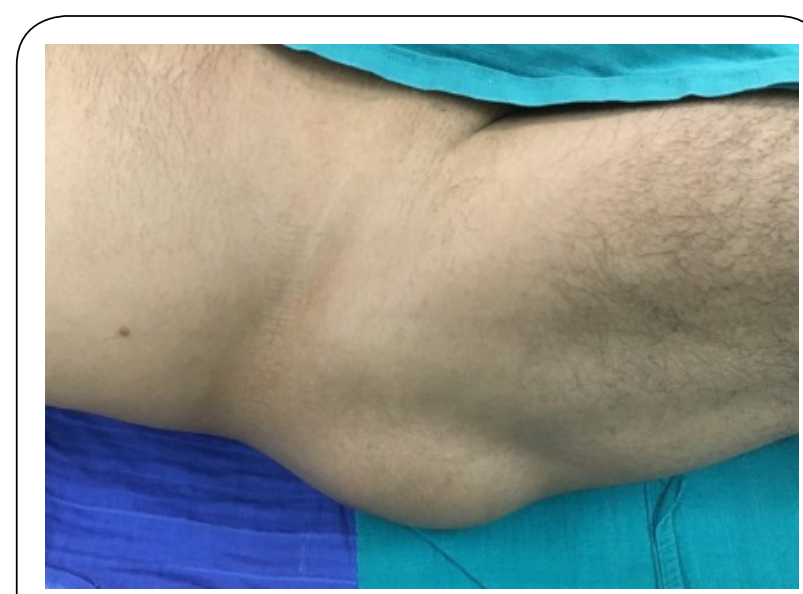

Figure 1. Preoperative clinical photograph showing the lump in the right buttock.

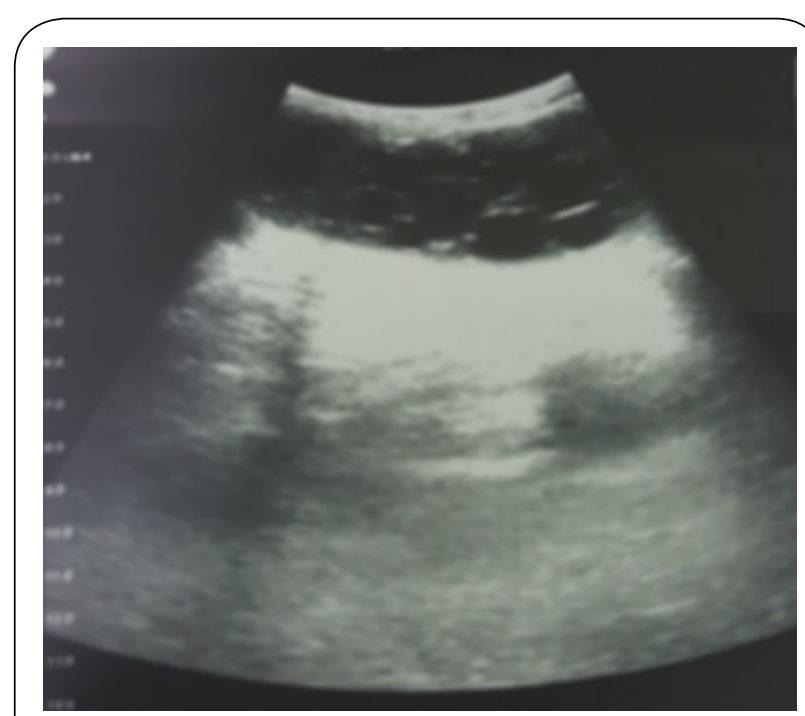

Figure 2. Heterogeneous mass within the stomach. tectomy (Figure 4). The subcutaneous cystic lesions were removed completely without damaging the cyst wall (Figure 5 and 6), and that extensive irrigation with hypertonic saline solution was performed. Histopathological examination confirmed the diagnosis of hydatidosis. Antihelminthic treatment with $2 \times 400$ mg of albendazole was administrated for two months to reduce the risk of relapse. One year postoperatively, the evolution was favorable. Clinical follow-up and repeated ultrasound controls were confirmed the absence of recurrence of the hydatid cyst.

\section{DISCUSSION}

Cystic hydatidosis is a cosmopolitan anthropozoonosis caused by Echinococcus granulosus. Parasitic infection is endemic in areas where sheep are raised in large quantities. Close contact with dogs is the main risk factor ${ }^{[3]}$. The Mediterranean region has been reporting cases regularly.

The liver and lungs are known as the most often sites involved $(85 \%)^{[2,5,6]}$. After ingestion, the ova of the parasite, which penetrates the mucosa of the small intestine, join the portal system and meet the liver and lungs. These organs filter out most ova. However, parasitic eggs can pass to the systemic circulation and reach other places in the body ${ }^{[7-9]}$. The mechanism of primary subcutaneous hydatidosis is not clear. Although larval subcutaneous colonization is a reliable mechanism, we believe that systemic dissemination through lymphatic channels should be considered ${ }^{[10]}$. Primary subcutaneous HC is an uncommon condition,

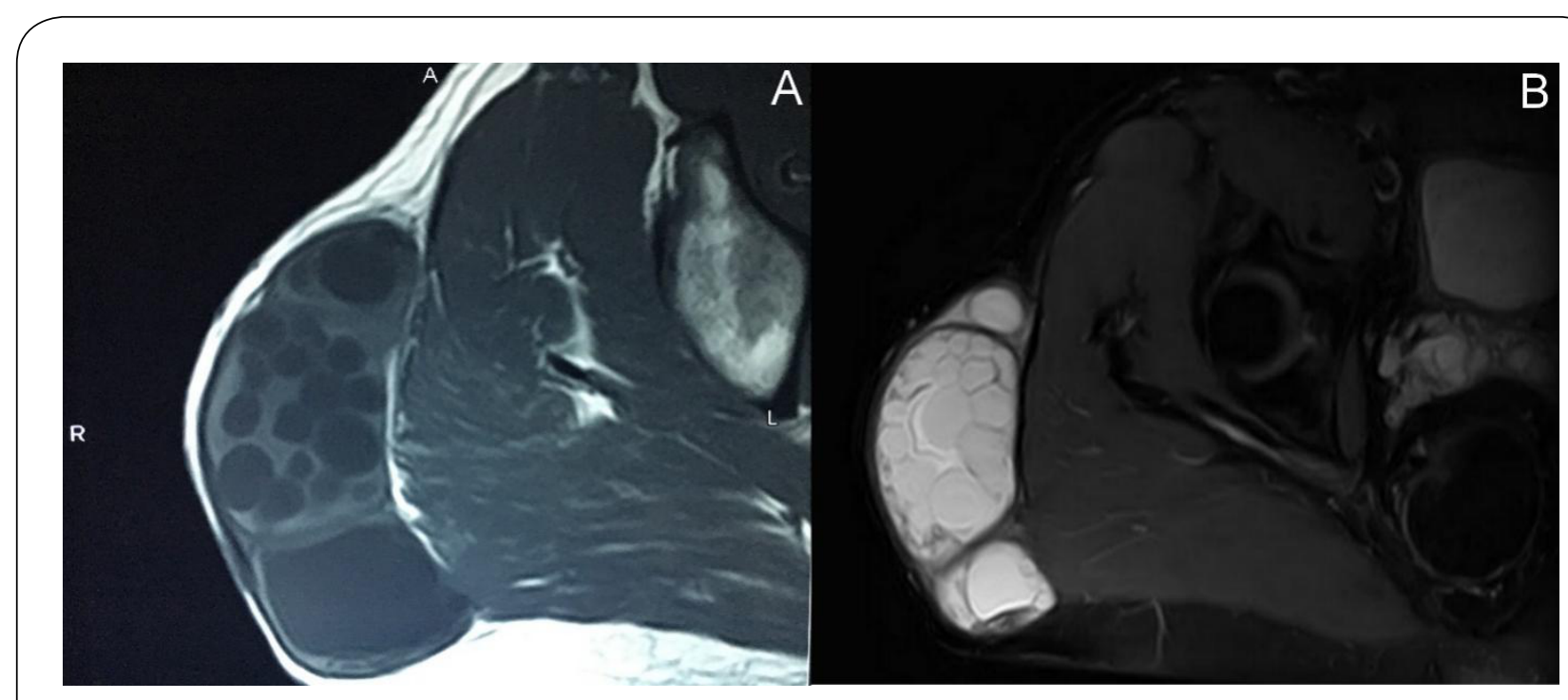

Figure 3. (A) Axial T1-weighted and (B) axial fat saturated T2-weighted magnetic resonance images showing subcutaneous multilocular cystic formation in the right buttock with daughter cysts. 


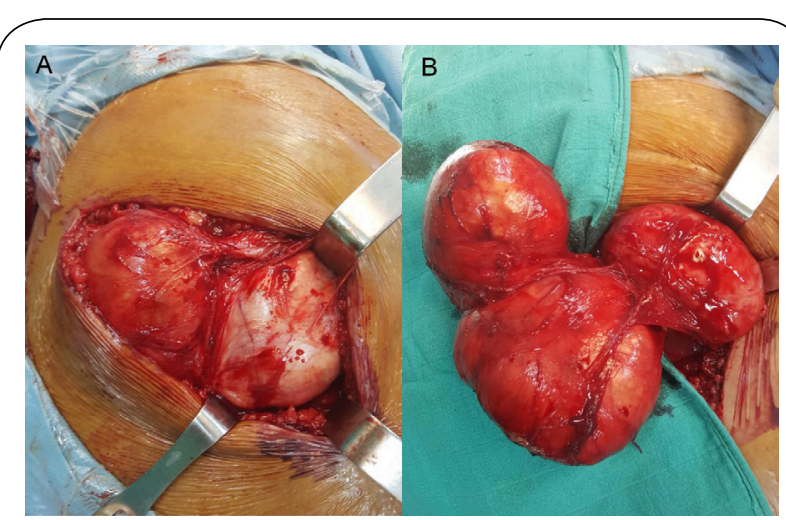

Figure 4. (A and B) Per-operative view of hydatid cyst operation

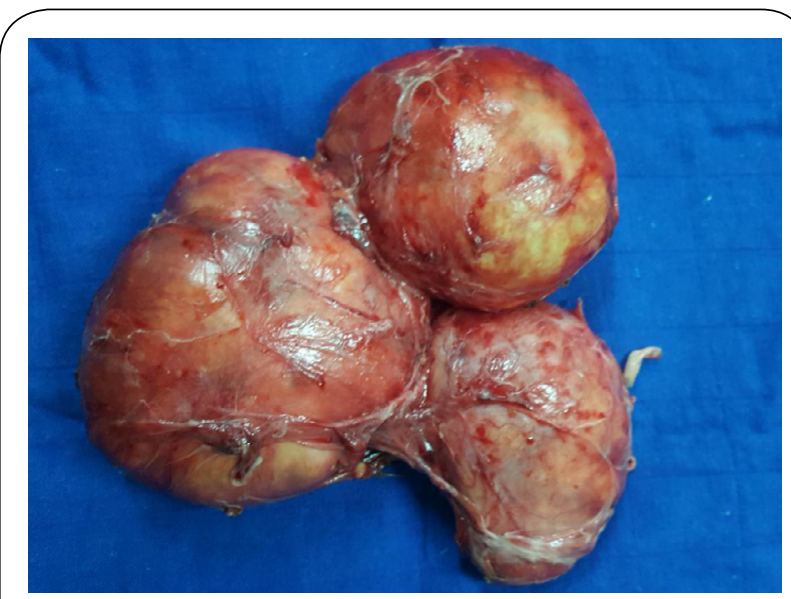

Figure 5. Macroscopic aspect of the totally excised hydatid cyst without destroying the cyst wall.

its gluteal localization makes only $1 \%$ of all the localization of the cyst (Table 1), with cold abscess, calcified hematoma, or lipoma as main differential diagnoses $[8,9,11]$. This involvement causes a diagnosis problem because of the insidious symptomatology; however, it's should be considered when slowly growing soft tissue mass in patients living in the endemic areas ${ }^{[12,13]}$. Because hydatid disease (HD) may develop complications

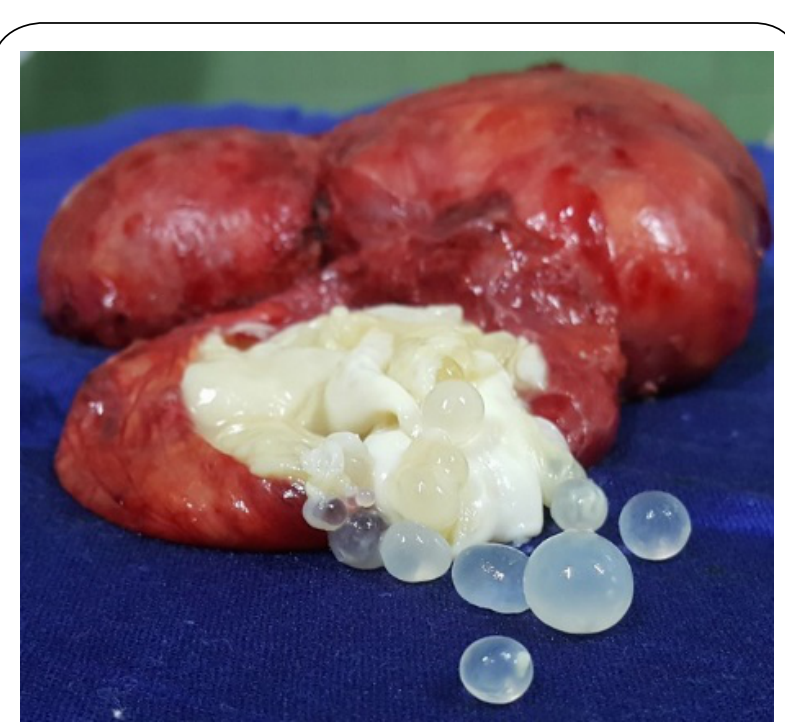

Figure 6. Image of several daughter cysts after opening of the main hydatid cyst.

such as rupture and anaphylactic reaction ${ }^{[14,15]}$, diagnosis of echinococcosis is required before any biopsy or surgical excision.

Ultrasonography is a useful key method for detecting hydatid cyst ${ }^{[8-10]}$. MRI is the better examination, which provides local and locoregional meticulous analysis ${ }^{[16]}$. Serological techniques are less sensitive for muscular involvements and can yield false-negatives ${ }^{[9,17]}$. In our case, the negative serological test does not exclude the diagnosis, and the imaging investigations have revealed a presentation of solitary primary subcutaneous hydatid cyst of the buttock.

Echinococcosis of the soft tissue is treated by surgery. Pericystectomy without perforing the cyst is the recommended option ${ }^{[7,8,11,18]}$. If this method is impossible to do without breaking the wall of the $\mathrm{HC}$, the cystic fluid has to aspire, and the laminated membrane should be totally excised. Sterilization of the cystic pouch is performed by protoscolicidal solutions ${ }^{[7-9,14]}$. In some

Table 1. Patients with isolated and primary subcutaneous hydatid cysts of the gluteal region and thigh ${ }^{[19-27]}$.

\begin{tabular}{|c|c|c|c|c|c|c|c|}
\hline Author & Year & $\begin{array}{c}\text { Sex of the } \\
\text { patient }\end{array}$ & $\begin{array}{l}\text { Age of the } \\
\text { patient }\end{array}$ & Localization & $\begin{array}{l}\text { Size of the } \\
\text { cyst }(\mathrm{cm})\end{array}$ & $\begin{array}{l}\text { Serologic test of } \\
\text { Echinococcus }\end{array}$ & Results after surgery \\
\hline Sreeramulu, P. N. & 2010 & $\mathrm{M}$ & 34 & Left gluteal & $12 / 10$ & Negative & No evidence of recurrence for 6 months \\
\hline Pathak, T. K. & 2011 & $\mathrm{~F}$ & 30 & Right thigh & $12 / 8$ & / & No local recurrence after one year \\
\hline Argy, N. & 2013 & $\mathrm{~F}$ & 60 & Right thigh & 10 & Positive & Relapse (three weeks later) \\
\hline Al-Hakkak, S. M. M & 2018 & M & 37 & Right thigh & $10 / 6.5$ & Positive & / \\
\hline Salih, A. M. & 2018 & $\mathrm{~F}$ & 34 & Left thigh & $10 / 17$ & Negative & / \\
\hline Samiee-Rad, F. & 2020 & M & 86 & Right thigh & $9 / 8 / 6.5$ & / & $\begin{array}{l}\text { No evidence of recurrence ( } 23 \text { months } \\
\text { follow-up) }\end{array}$ \\
\hline Zazo, R. & 2020 & $\mathrm{~F}$ & 36 & Right thigh & $12.4 / 8 / 11$ & Negative & $\begin{array}{l}\text { One month without any recurrence } \\
\text { manifestations }\end{array}$ \\
\hline Özdemir, M. & 2020 & M & 72 & Left gluteal & $4.4 / 3.4 / 4.6$ & Negative & No recurrence for 6 months \\
\hline Samsami, M. & 2021 & $\mathrm{~F}$ & 32 & Left thigh & $15 / 5$ & Negative & No recurrence during 8 months follow-up \\
\hline
\end{tabular}


cases, an additional perioperative antihelminthic therapy is preferred to reduce the risk of recurrence. Given our department guidelines, our patient underwent an antiparasitic medical treatment for 2 months after the surgical excision. We recommended 2 courses of oral Albendazole (400 mg twice per day) or $(12 \mathrm{mg} / \mathrm{kg} /$ day) for two months. Clinical and ultrasound periodic follow-up of our patient did not reveal any postoperative recurrence manifestations during 1 year.

\section{DECLARATIONS}

\section{Authors' contributions}

All authors made substantial contributions to merit inclusion as co-authors. All authors approved the final manuscript.

\section{Conflict of interest}

All authors declared that there are no conflicts of interest.

\section{Ethics approval}

Not applicable.

\section{Consent for publication}

Patient consent was obtained for publication without personal details.

\section{REFERENCES}

1. Kayaalp, C. (2007). Hydatid cyst of the liver. In Kayaalp C.Blumgart, L. H., \& Belghiti, J. (Eds.). Surgery of the Liver, Biliary Tract, and Pancreas(pp. 952-970).Philadelphia, PA: Saunders Elsevier.

2. Saidi, F. (1976). Surgery of hydatid disease. WB Saunders Company.

3. Eckert, J., \& Deplazes, P. (2004). Biological, epidemiological, and clinical aspects of echinococcosis, a zoonosis of increasing concern. Clinical microbiology reviews, 17(1), 107-135.

4. Kern, P., Bardonnet, K., Renner, E., Auer, H., Pawlowski, Z., Ammann, R. W., ... \& Kern, P. (2003). European echinococcosis registry: human alveolar echinococcosis, Europe, 1982-2000. Emerging infectious diseases, 9(3), 343.

5. Bal, N., Kocer, N. E., Arpaci, R., Ezer, A., \& Kayaselcuk, F. (2008). Uncommon locations of hydatid cyst. Saudi medical journal, 29(7), 1004-1008.

6. Yildirim, M., Erkan, N., \& Vardar, E. (2006). Hydatid cysts with unusual localizations: diagnostic and treatment dilemmas for surgeons. Annals of Tropical Medicine \& Parasitology, 100(2), 137-142.

7. Dirican, A., Unal, B., Kayaalp, C., \& Kirimlioglu, V. (2008). Subcutaneous hydatid cysts occurring in the palm and the thigh: two case reports. Journal of Medical Case Reports, 2(1), 1-4.

8. Ousadden, A., Elbouhaddouti, H., Ibnmajdoub, K. H., Mazaz, K., \& AitTaleb, K. (2011). A solitary primary subcutaneous hydatid cyst in the abdominal wall of a 70-yearold woman: a case report. Journal of Medical Case Reports, 5(1), 1-3.

9. Orhan, Z., Kara, H., Tuzuner, T., Sencan, I., \& Alper, M. (2003). Primary subcutaneous cyst hydatic disease in proximal thigh: an unusual localisation: a case report. BMC musculoskeletal disorders, 4(1), 1-4.

10. Ok, E., \& Sözüer, E. M. (2000). Solitary subcutaneous hydatid cyst: a case report. The American journal of tropical medicine and hygiene, 62(5), 583-584.

11. Rezakhaniha, B., \& Sirosbakht, S. (2010). Coincidental Hydatid Cyst of Skin and Kidney: A Very Rare Case Report. IRANIAN JOURNAL OF PATHOLOGY, 5(1), 47-50.

12. Marwah, S., Subramanian, P., Marwah, N., Rattan, K. N., \& Karwasra, R. K. (2005). Infected primary intramuscular echinococcosis of thigh. The Indian Journal of Pediatrics, 72(9), 799-800.

13. Erol, B., Tetik, C., Altun, E., Soysal, A., \& Bakir, M. (2007). Hydatid cyst presenting as a soft-tissue calf mass in a child. European journal of pediatric surgery, 17(01), 5558.

14. Duncan, G. J., \& Tooke, S. M. (1990). Echinococcus infestation of the biceps brachii. A case report. Clinical orthopaedics and related research, (261), 247-250.

15. Rao, S., Parikh, S., \& Kerr, R. (1991). Echinococcal infestation of the spine in North America. Clinical orthopaedics and related research, (271), 164-169.

16. Garcia-Diez, A. I., Mendoza, L. R., Villacampa, V. M., Cozar, M., \& Fuertes, M. I. (2000). MRI evaluation of soft tissue hydatid disease. European radiology, 10(3), 462-466.

17. Hernández-González, A., Muro, A., Barrera, I., Ramos, G., Orduna, A., \& Siles-Lucas, M. (2008). Usefulness of four different Echinococcus granulosus recombinant antigens for serodiagnosis of unilocular hydatid disease (UHD) and postsurgical follow-up of patients treated for UHD. Clinical and Vaccine Immunology, 15(1), 147-153.

18. Ates, M., \& Karakaplan, M. (2007). Hydatid cyst in the biceps and gluteus muscles: case report. Surgical infections, 8(4), 475-478.

19. Sreeramulu, P. N. (2010). Gluteal region musculoskeletal hydatid cyst: Case report and review of literature. Indian Journal of Surgery, 72(1), 302-305.

20. Pathak, T. K., Roy, S., Das, S., Achar, A., \& Biswas, A. K. (2011). Solitary hydatid cyst in thigh without any detectable primary site. JPMA-Journal of the Pakistan Medical Association, 61(12), 1244.

21. Argy, N., Abou Bacar, A., Boeri, C., Lohmann, C., Pfaff, A. W., Hansmann, Y., ... \& Lefebvre, N. (2013). Primary musculoskeletal hydatid cyst of the thigh: Diagnostic and curative challenge for an unusual localization. Canadian 
Journal of Infectious Diseases and Medical Microbiology, 24(3), e99-e101.

22. Al-Hakkak, S. M. M. (2018). Adductor magnus muscle primary hydatid cyst rare unusual site: A case report. International journal of surgery case reports, 51, 379-384.

23. Salih, A. M., Kakamad, F. H., Salih, R. Q., Rahim, H. M., Habibullah, I. J., Hassan, H. A., \& Mikael, T. M. (2018). Hydatid cyst of the thigh: A case report with literature review. International journal of surgery case reports, 51, 8-10.

24. Samiee-Rad, F., \& Emami, A. (2020). An Iranian man with increased thigh mass due to a hydatid cyst. GMS Hygiene and Infection Control, 15.
25. Zazo, A., Zazo, R., Shashaa, M. N., Alkarrash, M. S., Alsaman, M. Z. B., \& Niazi, A. (2020). Uncommon musculoskeletal femoral hydatid cyst disturbs a female for a year: Case report. Annals of Medicine and Surgery, 55, 30-32.

26. Özdemir, M., Kavak, R. P., Kavak, N., \& Akdur, N. C. (2020). Primary gluteal subcutaneous hydatid cyst. IDCases, 19, e00719.

27. Samsami, M., Qaderi, S., Bagherpour, J. Z., \& LuceroPrisno III, D. E. (2021). A case report of primary isolated extrahepatic hydatid cyst of the soft tissues of the breast and thigh. International Journal of Surgery Case Reports, $79,475-478$. 